\title{
CONSELHOS MUNICIPAIS DE EDUCAÇÃO NO BRASIL: DISCUSSÕES SOBRE SEU SURGIMENTO E DESENVOLVIMENTO
}

\author{
Md. Gilsemara Vasques Rodrigues Almenara \\ Universidade Federal de São Carlos [UFSCar] - Campus Sorocaba \\ Dr. Paulo Gomes Lima \\ Universidade Federal de São Carlos [UFSCar] - Campus Sorocaba
}

\begin{abstract}
RESUMO: A presente pesquisa discute o surgimento e desenvolvimento dos conselhos municipais de educação no Brasil, os percalços e encaminhamentos para a sua constituição. Em seu conjunto são trazidas discussões sobre os elementos imprescindiveis de legitimação dos Conselhos Municipais de Educação centrados na participação, gestão democrática e autonomia. Trata-se de uma pesquisa exploratória de caráter bibliográfica organizada em três seções: a). Os conselhos municipais de educação no Brasil: desdobramentos históricos, b) Qualidade socialmente referenciada, participação e democracia no centro do debate dos conselhos municipais de educação e c)
\end{abstract}

Perspectivas de gestão democrática nos CME: algumas pontuações. Em sua dimensão conclusiva, o estudo revelou que educação se torna uma síntese entre igualdade e diferença. Mais do que meros executores de políticas, os cidadãos querem ser ouvidos nos momentos de elaboração das políticas públicas, assim como, nos momentos de tomadas de decisão. A participação é a forma concreta da democracia e os colegiados, como seus canais de legitimação devem ser trabalhados com vistas a lutar pelo direito e justiça social de seus munícipes, sendo o Conselho Municipal de Educação, instância e espaço propício para esta finalidade.

PALAVRAS-CHAVE: Conselho municipal de educação. Gestão democrática. Qualidade socialmente referenciada.

\section{MUNICIPAL COUNCILS OF EDUCATION IN BRAZIL: DISCUSSIONS ABOUT ITS EMERGENCE AND DEVELOPMENT}

\begin{abstract}
The present research discusses the emergence and development of municipal councils of education in Brazil, the mishaps and referrals to its constitution. Discussions are brought about the essential elements of legitimization of the Municipal Councils of Education centered on participation, democratic management and autonomy. This is an exploratory bibliographic research organized in three sections: a) The municipal councils of education in Brazil: historical developments, b) Socially referenced quality, participation and democracy at the center of the debate of the municipal councils of education, and c)
\end{abstract}

Perspectives of democratic management in CME: some scores. In its conclusive dimension, the study revealed that education becomes a synthesis between equality and difference. More than mere policy makers, citizens want to be heard in the moments of public policy making, as well as in moments of decision-making. Participation is the concrete form of democracy and the collegiate, as its channels of legitimation must be worked with a view to fighting for the right and social justice of its citizens, the Municipal Council of Education, instance and space conducive to this purpose.

KEYWORDS: Municipal council of education. Democratic management. Socially referenced quality. 


\section{Educere "Educare \\ ReVISTA DE EduCAČ̃̃o}

Programa de Pós-Graduação em Educação - Universidade Estadual do Oeste do Paraná

\section{INTRODUÇÃO}

A Constituição de 1934, pela primeira vez anuncia na organização da educação brasileira o caráter sistêmico, inspirada pelos Pioneiros da Educação Nova. Entendendo a educação em sua totalidade e como bases para um projeto nacional de cidadania, pois a situação da educação naquele momento histórico era considerada caótica, diante da fragmentação e descontinuidade em termos de educação brasileira. Desta forma, o Manifesto evidencia sua inquietação a respeito desta situação fracionada em que se encontrava a educação brasileira. O Manifesto advogava que a politica educacional devia buscar a coerência interna e unidade na multiplicidade. Nele não era proposta, explicitamente, a organização dos atuais sistemas de ensino, mas todo o seu teor continha essa concepção. O termo sistema aparece nele de forma genérica, referindo-se a sistema escolar e ao “[...] erro capital que apresenta o atual sistema (se é que se pode chamar sistema) ", (BORDIGNON, 2009, p.30).

O Manifesto impactou e contribuiu para que a Constituição de 1934 viesse a instituir os sistemas educativos e os conselhos de educação (federal e estadual). A união é incumbida neste momento de elaborar o Plano Nacional de Educação (PNE), por meio do Conselho Nacional de Educação (CNE), Plano que traria a concepção de sistema nacional e forma de lei geral da educação, entretanto, nesse momento não a concepção de plano nacional. Todavia, o centralismo da doutrina federativa emperra naquele momento o escopo de uma lei geral da educação, vindo a tomar corpo e sendo homologada apenas muitos anos após a Constituição de 1934.

Por um lado, se em lei, pistas da organização sistêmica da educação brasileira eram previstas, por outro, interrompe-se, por mais duas décadas (de 1964 a 1985), a busca por tal empenho. Ainda que mantidos os sistemas de ensino na Constituição de 1967, duas outras leis rompem a origem unificadora da Lei de Diretrizes e Bases da Educação Nacional, a saber, a Lei n ${ }^{\circ}$ 5.540/68-ensino 


\section{Educere "Educare \\ Revista de EduCAČ̃̃o}

Programa de Pós-Graduação em Educação - Universidade Estadual do Oeste do Paraná

superior, e a Lei no 5.692/71-para a educação básica. Esta última no art. 71 abre a possibilidade dos Conselhos Estaduais de Educação em delegar parte de suas atribuições aos Conselhos de Educação, caso existissem nos municípios. Lembrando que os municípios somente vão galgar o status de autonomia administrativa a partir da Constituição de 1988. Ora, vê-se que no município até então, isto é, naqueles que porventura apresentassem seus Conselhos de Educação, teriam uma legitimidade em desempenhar parte outorgada do que caberia aos Conselhos Estaduais de Educação, uma vez que ainda não possuíam autonomia para criar seus sistemas de ensino, assim, a estes municípios eram delegadas competências tuteladas, à luz e sob a diretriz dos conselhos estaduais.

Apenas com a Constituição de 1988 os municípios surgem como entes federados com autonomia e instituem os sistemas municipais de ensino, conquistas decorrentes da grande participação da sociedade civil nos debates da constituinte, evidenciando no contexto político, a busca por um Estado democrático de direito, e a supressão da ditadura civil-militar instaurada até então. No artigo 18, a nova Constituição de 1988 estabelece a autonomia dos entes federados. No artigo 211, a organização dos sistemas de ensino é prevista, tendo como eixo o regime de colaboração, o que deveria ser estabelecido com base em acordos entre os entes, garantindo-se o princípio anterior de autonomia. A LDBEN (n.9.394/96), no parágrafo único do artigo 11, permite ao município que não quiser constituir sistema próprio optar "[...] por se integrar ao sistema estadual de ensino ou compor com ele um sistema único de educação básica”. Portanto, Constituição e LDB definem uma relação de colaboração e não de hierarquização, entre os sistemas de ensino entre os entes federados que em sua totalidade consiste no Sistema Nacional de Educação. As Diretrizes e Bases da Lei da Educação, ao se remeter ao princípio de organização intencional por meio de autonomia entre os entes, chancelam o alcance dos fins educacionais por meio de suas políticas educacionais encampadas por seus projetos e expectativas (BRASIL, 1996). 


\section{Educere "Educare \\ Revista de EduCAČ̃̃o}

Programa de Pós-Graduação em Educação - Universidade Estadual do Oeste do Paraná

Assim, os sistemas educacionais em suas distintas esferas (federal, estadual e municipal), devem ter como centralidade o estabelecimento do projeto educacional solicitado pela agenda da sociedade brasileira, a partir da Constituição e da Lei de Diretrizes e Bases da Educação nacional em vigor, abrindo possibilidades de contemplar dimensões mais ampliadas, conforme a leitura de sua realidade. Um indicador constitucional desse olhar está na garantia do fundamento democrático do exercício da cidadania e consequentemente da participação popular nos processos que contemplam o interesse da sociedade no âmbito da educação. Os conselhos considerados espaços públicos de composição plural e paritária entre Estado e sociedade civil, é de natureza deliberativa e consultiva, e tem a função de formular e controlar a execução das políticas públicas em seus diversos setores: "Um Conselho de Educação é, antes de tudo, um órgão público voltado para garantir, na sua especificidade, um direito constitucional da cidadania." (CURY, 2006 p. 41).

São eles um dos principais espaços de participação popular encontrada nas três instâncias de governo (federal, estadual e municipal). Os conselhos gestores de politicas públicas são canais efetivos de participação, que oportunizam instalar uma sociedade onde a cidadania, para além do direito, seja uma realidade, ainda que sob a diretiva de uma gestão democrática numa perspectiva de autonomia relativa. A importância dos conselhos centra-se em seu papel de fortalecimento da participação democrática da população na formulação e implementação de políticas públicas.

Os conselhos de educação tiveram uma atuação essencial na organização dos sistemas educacionais no Brasil, considerando suas esferas. São exemplos de sua contribuição: a formalização estrutural dos sistemas e a uniformização do modelo de escolas consagrado no país, a normatização do processo de ensino, estabelecendo as bases para o seus princípios, acompanhamento e avaliação, dentre outros. Por conta da compreensão dos canais que legitimam a gestão democrática à luz da Constituição e LDBEN, pode-se afirmar que o papel dos 


\section{Educere Educare \\ Revista de EduCAČ̃̃o}

Programa de Pós-Graduação em Educação - Universidade Estadual do Oeste do Paraná

Conselhos de Educação, mais particularmente os Conselhos Municipais de Educação, para o qual foram criados, construindo conhecimentos sobre a organização e a administração do ensino, definindo rumos, criando alternativas de ação vem tomando significativo vulto na realidade brasileira (TEIXEIRA, 2004, p. 701). O contraponto dessa perspectiva também ocorre conforme os interesses de grupo e ausentamento de representatividade popular.

Nesse sentido, por vezes, os conselhos desenvolvem modelos mais burocráticos e cartoriais em suas ações, legitimando parcialmente as demandas que deveriam ser examinadas em sua integralidade. Daí fazer-se lembrar que o equilíbrio que pode recuperar o debate centra-se na participação e estabelecimento de agenda de mobilizações no contexto dos interesses da comunidade, por meio de seus representantes orgânicos. Experiências de conselhos de educação são verificadas em diferentes municipios brasileiros, mesmo que sem a constituição dos sistemas municipais de ensino, algumas delas bem antigas datadas de 1980, e outras mais recentes, como observaremos no tópico posterior.

Vale lembrar que, Allebrandt (2003, p. 3) considera que a existência formal de conselhos, mesmo que instalados e com conselheiros escolhidos e nomeados, não garante que eles realmente funcionem, ou, ainda que funcionando, sejam eficientes e eficazes como instrumentos de aperfeiçoamento da cidadania e exercício da gestão democrática e atuantes como formuladores ou pelo menos participantes ativos do processo de formação da agenda das políticas públicas. Por isso a importância de se refletir a respeito do funcionamento destes conselhos gestores, suas trajetórias históricas e formas de atuação. Uma vez normatizada a criação do conselho, o debate incide sobre suas ações concretas e sua gestão, observa-se agora o grau de representatividade e de influência nas políticas públicas, como se dá a participação e quais os obstáculos que devem ser superados. 


\section{Educere "Educare \\ Revista de EduCAČ̃̃o}

Programa de Pós-Graduação em Educação - Universidade Estadual do Oeste do Paraná

\section{OS CONSELHOS MUNICIPAIS DE EDUCAÇÃO NO BRASIL: DESDOBRAMENTOS HISTÓRICOS}

A existência dos conselhos no contexto educacional brasileiro remonta ao tempo do império e transversaliza o período republicano, por meio de diferentes concepções e respectivas formas de organização orientado pela lógica de produção, o que necessariamente desencadeou historicamente recorrências entre os cidadãos e o Estado. Destaca-se no contexto da história da educação brasileira, a criação de dois conselhos que podem ser considerados antecessores à criação do Conselho Nacional do Ensino (1925) - Reforma de Rocha Vaz - responsável também pela criação do Departamento de Educação no Ministério da Justiça e Negócios Interiores. São estes dois conselhos: Conselho Superior de Instrução Pública (1891) e o Conselho Superior de Ensino, instituído pela Reforma Rividávia em 1911 (Decreto n. 8.659/1911). Estes conselhos delinearam um perfil de órgãos fiscalizadores dos estabelecimentos de ensino superior mantidos pela União, contando em sua composição com membros desses estabelecimentos, numa perspectiva administrativa centralizadora e patrimonialista, como se desenham os percursos da formação do Estado brasileiro.

A legislação que norteou as ações, tanto do Conselho Nacional de Ensino (1925), como do Conselho Nacional de Educação (1931), destacou o caráter administrativo à eles concedido, embora entre um e outro possamos notar mudanças importantes em suas atribuições. O conselho de 1925 realizava ações que o situava como órgão de execução da administração do ensino secundário, e era composto de três seções (Conselho do Ensino Secundário e do Superior, Conselho do Ensino Artístico e Conselho do Ensino Primário e Profissional), era considerado o órgão de execução da administração do ensino. Por sua vez, Conselho Nacional de Ensino é recriado em 1931 com o nome de Conselho Nacional de Educação (CNE), após a criação do Ministério de Educação e Saúde Pública no mesmo ano, neste momento histórico o caráter técnico é inserido, sem descartar sua função administrativa, ainda que no Decreto n. 19.850/31 estivesse 


\section{Educere "Educare \\ Revista de EduCAČ̃̃o}

Programa de Pós-Graduação em Educação - Universidade Estadual do Oeste do Paraná

evidente que este órgão "[...] não terá atribuições de ordem administrativa", passando a ter, portanto uma função consultiva a respeito de "assuntos técnicos e didáticos”. (CURY, 2004, p. 36).

Estas definições refletem também na composição de seus membros que segundo o artigo $3^{\circ}$ do mesmo Decreto deveriam ser "[...] pessoas de reconhecida competência para as funções e, de preferência, experimentadas na administração do ensino e conhecedoras das necessidades nacionais". A função técnica do Conselho Nacional do Educação, portanto, se revelaria pontualmente com a regulamentação estabelecida pela Lei n. 174/36, identificando-a como órgão colaborador do Poder Executivo, cuja principal atribuição seria a elaboração do Plano Nacional de Educação - PNE. Logo, a lógica funcional do Conselho refletia a recorrência das vozes da sociedade brasileira de então, legitimamente representada. Nas competências desse órgão houve inicialmente uma concepção modernizadora (ROCHA, 2000, p. 45 apud TEIXEIRA, 2004. p. 695), centradas nas ideias escolanovistas, influência do Manifesto dos Pioneiros de 1932, presente na constituinte de 1934 e nas reformas de ensino das décadas de 30 a 60. Tal concepção orientou a função normativa do CNE para o setor da educação, que passou a ganhar grande importância a partir da Reforma Francisco Campos, sendo então responsável pela organização da estrutura do ensino no país. Saviani (1999; 2010) afirma que o Manifesto dos Pioneiros da Educação Nova pode ser considerado como referência para as gerações subsequentes ao século XX, pelo seu caráter inovador, ainda que não refletisse o desejo real de modificação da estrutura política do país por seus dirigentes.

O CNE, a partir de então ocupa papel especial na constituição legal do sistema educacional brasileiro quanto ao acompanhamento, dimensão normativa ainda que relativizada e consultiva no que consistia na organização do ensino, definição de direitos, determinação de competências e oportunizações para o exercício da cidadania (centrado na ideia de cidadania enquanto valor econômico). Um pouco mais adiante, com a aprovação da Lei de Diretrizes e Bases (LDB), $n$. 


\section{Educere "Educare \\ Revista de EduCAČ̃̃o}

Programa de Pós-Graduação em Educação - Universidade Estadual do Oeste do Paraná

4.024/61 são instituídos os sistemas federal e estadual de ensino e inaugura-se o Conselho Federal de Educação ( $\mathrm{CFE}$ ), esse passo formaliza a criação de conselhos similares nos Estados, os Conselhos Estaduais de Educação (CEE). No Art. $7^{\circ}$ da LDB n.4024/61, é previsto a responsabilidade do Ministério da Educação e Cultura, de "[...] velar pela observância das leis do ensino e pelo cumprimento das decisões do Conselho Federal de Educação [...]", criando assim, pela primeira vez, o caráter de órgão deliberativo dessa instância. (CURY, 2004, p. 36).

No Art. $8^{\circ}$, a Lei 4.024/61 assevera que, o CFE deveria ser composto "[...] de pessoas de notável saber e experiência em matéria de educação". Sendo assim, a seleção de 24 membros de várias regiões do país, sendo estes, profissionais do ensino de diferentes ramos e modalidades, garantem a representatividade. Portanto, a reforma do ensino posta pela LDB de 1961, coloca como encargo do $\mathrm{CFE}$, a incumbência de organizar e colaborar com o funcionamento dos sistemas federal e estadual de ensino, revestindo-o de um caráter normativo, reforçado pelo poder executivo dos governos militares a partir de 1964. O caráter normativo dos conselhos de educação acentua-se com a Lei n. 5.692/71 e se expande, na medida em que a eles são atribuídas competências para organizar os currículos de ensino, assim como adequá-los às características locais e regionais. A mesma lei, ainda faculta em seu Art. 71, que os municípios constituam seus próprios conselhos de educação, que receberão dos conselhos estaduais as respectivas competências. Ora, até então, não se tem como referência a participação popular nos conselhos, mas a de especialistas representantes de regiões brasileiras. Claro que o quadro apresentado se refere na leitura da realidade brasileira que teria mais adiante a busca pela inclusão e ampliação da categoria participação, reduzida na ditadura civil-militar.

Na década de 1980, a sociedade civil brasileira em busca da democratização propõe a participação em diferentes instâncias da administração pública, e infunde a constituição de conselhos municipais de educação como locais de 


\section{Educere "Educare \\ Revista de EduCAČ̃̃o}

Programa de Pós-Graduação em Educação - Universidade Estadual do Oeste do Paraná

discussão e participação das questões de educação. Os princípios de gestão democrática do ensino público e de garantia de padrão de qualidade (art. 206, VI e VII), a afirmação da educação como direito público subjetivo (art. 208, § $1^{\circ}$ ) e a descentralização administrativa do ensino (art. 211) fortaleceram a concepção dos órgãos colegiados na estrutura de ensino e alimentaram as expectativas em favor da constituição de conselhos de educação mais representativos (TEIXEIRA, 2004, p. 698), onde os olhares e encaminhamentos dos colegiados pudessem colocar na agenda do dia as demandas sociais. A CF/1988 rompe com autoritarismo decorrente da ditadura e sinaliza a necessidade da Lei de Diretrizes e Bases da Educação Nacional normatizar o princípio de gestão democrática do ensino público, assim há recorrência legal que estabelece a criação de instrumentos de controle e fiscalização dos recursos destinados à educação, fato que impulsionou a proliferação dos Conselhos Municipais de Educação no Brasil.

Portanto, a regulação dos dispositivos constitucionais de 1988, se concretiza em 1996, quando ocorre a promulgação da nova LDBEN - Lei 9.394/96 (BRASIL, 1996), que ratifica, segundo Gohn $(2006$, p. 43) a organização sistêmica, e normatiza a condição de sistemas autônomos atribuída aos Municípios pela CF 1988, desta forma, a organização sistêmica anterior que estava prevista no âmbito das três esferas de governo (Federal, do Distrito Federal e Estadual), passa a ser composta, agora, por quatro, caracterizando sistemas autônomos e com incumbências e prioridades diferenciadas: o sistema Federal de ensino; o sistema de ensino do Distrito Federal; o sistema de ensino dos Estados e o sistema de ensino dos Municipios, garantidos, pelo menos no âmbito legal, o Regime de Colaboração entre eles.

No entendimento de Gohn (2002; 2006), um novo paradigma se instala no contexto dos anos 1990 - a participação - agora baseada na universalização dos direitos, no conceito de cidadania e em um novo olhar sobre o caráter do Estado, sendo assim considerada, "participação cidadã", afinal esta participação ocorreria então durante a formulação e a implementação de políticas públicas, visando a 


\section{Educere "Educare \\ Revista de EduCAČ̃̃o}

Programa de Pós-Graduação em Educação - Universidade Estadual do Oeste do Paraná

transformação social. A Constituição Federal de 1988 em seu Art. $2^{\circ}$, fortalece o vetor acerca da participação da sociedade civil nas políticas públicas quando institui: "A educação, direito de todos e dever do Estado e da família, será promovida e incentivada com a colaboração da sociedade, visando ao pleno desenvolvimento da pessoa, seu preparo para o exercício da cidadania e sua qualificação para o trabalho".

Concomitantemente, o Art.13 da LDB, traz em seu inciso III o sentido da escola pública: o de zelar pela aprendizagem dos alunos. E porque o conhecimento é fundamental para todos, o Estado e seus agentes têm o dever de garantir o ensino e padrão de qualidade que faça cumprir a finalidade da educação nacional, inciso IX do Art 3º, LDB n 9394/96 (BRASIL, 1996).

A participação da sociedade nas instâncias locais, como fazer-se presente no conselho escolar e no conselho municipal de educação, abre espaço, mesmo que seja conflitual, para o debate em torno da qualidade que se espera da educação e se empenha em alcançá-la (LOPES, 2016, p. 9383). Ora, por meio do Colegiado socialmente referendado e tendo a gestão democrática e a participação como princípios fundamentais, a discussão dos Conselhos Municipais de Educação, o seu acompanhamento e o desenvolvimento de suas atribuições devem encampar esforços para a consolidação e consistência da expectativa social como observaremos a seguir.

\section{QUALIDADE SOCIALMENTE REFERENCIADA, PARTICIPAÇÃO E DEMOCRACIA NO CENTRO DO DEBATE DOS CONSELHOS MUNICIPAIS DE EDUCAÇÃO}

O termo "qualidade", além de ser passivel de diferentes interpretações, carrega consigo, também, quando aplicado à educação, diferentes contextos teóricos e políticos aos quais se vincula. Este trabalho problematiza tanto o próprio conceito de qualidade, que não é único ou neutro, quanto a necessidade da gestão democrática na escola para a construção de uma qualidade na educação 


\section{Educere "Educare \\ Revista de EduCAČ̃̃o}

Programa de Pós-Graduação em Educação - Universidade Estadual do Oeste do Paraná

socialmente referenciada e a participação como eixo de legitimação das demandas sociais. A qualidade é normalmente tomada como atributo que qualifica um dado objeto, conferindo-lhe certas características que o distinguem de outro objeto. É, portanto, um conceito relacional de valoração que exige comparações, ainda mais quando se busca avaliar se um processo foi desenvolvido com boa ou má qualidade. A avaliação da qualidade, ao deslocar-se do foro individual e debruçarse sobre questões sociais, passa, inevitavelmente, pelo debate coletivo, já que os diferentes contextos sociais, econômicos e políticos dos indivíduos produzirão diferentes formas de encarar a qualidade. (AZEVEDO, 2011, p. 422).

A qualidade em educação que foi defendida, no Brasil, a partir dos anos 1980 e mais acentuadamente posta em prática nas reformas educacionais dos anos 1990, conhecida como "qualidade total", vinculava-se, conforme Gentili (1999), a certa concepção de mundo própria do universo empresarial, em que se destacava um ideal de eficiência e produtivismo dirigido aos interesses do mercado.Toda visão do que seja qualidade traz junto consigo mecanismos de avaliação dessa mesma qualidade. Logo, a partir desse modelo de qualidade empresarial e tecnicista na educação, surgem testes padronizados e em larga escala, como os referendados pelo Sistema de Avaliação da Educação Básica (SAEB), estabelecendo a lógica da competição, própria dos modelos de gestão privada, ao efetivar o "ranqueamento" das escolas públicas, o que promove discriminação, exclusão social e aprofundamento das desigualdades, instaurando, assim, a ênfase no resultado, no produto escolar, e não mais no processo. Morre, então, o ideal do "Estado provedor" e nasce o "Estado avaliador", ausentando-se, cada vez mais, do controle direto sobre os processos educacionais ao apropriar-se dos princípios da administração pública gerencial (BARROSO, 2005).

Por outro lado, houve e há, ainda hoje, resistências de parte da sociedade a esse viés mercadológico de qualidade, estabelecendo uma disputa em torno desse termo, evidenciando que não há uma qualidade universal, neutra, sem 


\section{Educere "Educare \\ Revista de EduCAČ̃̃o}

Programa de Pós-Graduação em Educação - Universidade Estadual do Oeste do Paraná

intencionalidades políticas que refletem, por sua vez, diferentes visões de mundo. O que se encontra em choque, por trás da disputa da "qualidade", são diferentes modelos de "sociedade" e do "homem" que se deseja formar. (DAVOK, 2007, p. 506). Partindo, portanto, da compreensão de que "qualidade" não é um conceito absoluto, é importante que se tenha clareza de qual qualidade se busca na educação, pois esta pautará, em grande medida, os objetivos do projeto educativo (formar para o mercado ou para uma tipologia social que reflita a vida social?), seu modo de formação (mais ou menos democrático), sua abrangência e escopo (isolada nas questões internas da escola ou conectada ao seu entorno e às questões da política nacional de educação).

A qualidade na educação deve ser construída e avaliada enfrentando-se essas tensões e contradições próprias do fazer social, a partir dos parâmetros gerais estabelecidos nacionalmente, mas em negociação com as necessidades locais, compreendendo-se a comunidade escolar num fluxo dinâmico entre o micro e o macro, referenciando-a, portanto, socialmente, tendo por construto basilar o diálogo e a participação numa gestão democrática da educação. Ao focar apenas em critérios mercadológicos para pensar a qualidade da educação e sua avaliação (tecnicismo com medidas descontextualizadas e generalizantes), a gestão pública torna-se refém dos interesses do capital e dos negócios, desprezando as questões sociais e de ordem regional e comunitária, que, assim, tendem a se agravar. A qualidade e a avaliação devem englobar o complexo educativo, envolvendo diferentes sujeitos internos e externos. (PARO, 1997, p. 94). É necessário pensar a qualidade observando-se o processo histórico de nossa sociedade, entendendo as desigualdades entre classes e o modelo de exclusão vigente em que a grande maioria da população se encontra. Não se pode retirar dessa população o direito a uma formação humana omnilateral (FRIGOTTO, 1996), que vem sendo sequestrado pelo discurso da formação técnica para o mercado. Por isso, é fundamental pensar a qualidade na educação de forma mais ampla e complexa, como socialmente referenciada. (SILVA, 2009). 


\section{Educere "Educare \\ Revista de EduCAČ̃̃o}

Programa de Pós-Graduação em Educação - Universidade Estadual do Oeste do Paraná

Pensar a qualidade socialmente referenciada necessária para a educação é pensar a complexidade social da escola, com seus objetivos formativos específicos, mas, também, a partir de valorações e marcos mais amplos da sociedade e comunidade em que está inserida. A escola, como instituição social, não se restringe apenas à sua capacidade de mediar o desenvolvimento de conhecimentos e habilidades dos alunos, mas resulta de uma intrincada negociação, entre diferentes setores e classes, acerca de qual sociedade se deseja construir. Por isso mesmo, a qualidade almejada para a educação envolverá, inevitavelmente, confrontos políticos e ideológicos, o que torna necessária a mediação social dessa qualidade, através de mecanismos internos coletivos (como o Projeto Político Pedagógico) e instâncias externas de debate (como os Conselhos de Educação em seus diversos níveis).

Partindo-se da necessidade da qualidade socialmente referenciada entendese que a escola deve trabalhar os estudantes para a leitura de e atuação no seu real consistindo na formação para e por meio do trabalho no sentido mais amplo de sua autoprodução, da identificação dos contextos adversos do mercado e suas solicitações, além de uma formação humana indagadora e reflexiva, e, acima de tudo, para a vida em sociedade em seus diferentes aspectos e desafios. (FONSECA, 2009 , p. 173). A busca pela qualidade socialmente referenciada abarca tanto os fatores internos à escola, quanto os externos, o que obriga a olhar o processo de escolarização de forma mais profunda, para além da instituição que isolada do meio não consegue se ver e se refletir. No interior da escola, a qualidade social da educação é respaldada por um conjunto de fatores como: o respeito às diferenças; diálogo entre escola e famílias; a organização do trabalho pedagógico e gestão da escola; seus projetos; estrutura, organização técnica e pedagógica, formação docente etc.

As politicas nacionais, estaduais e municipais de educação, construídas fundamentalmente fora da escola, também devem ser abarcadas pela comunidade escolar, assim como o debate acerca das condições de existência e permanência 


\section{Educere "Educare \\ Revista de EduCAČ̃̃o}

Programa de Pós-Graduação em Educação - Universidade Estadual do Oeste do Paraná

de todos os sujeitos dessa comunidade (professores, alunos, funcionários, gestores). Tendo em vista essa complexidade de fatores sociais (macro e micro) e de diferentes sujeitos envolvidos com o desenvolvimento da qualidade socialmente referenciada na educação, ressalta-se, em especial, um elemento chave, que deve mediar todos esses processos para que haja, realmente, construção social e coletiva da qualidade: a gestão democrática.

Um outro eixo, a gestão democrática como processo de aprendizado da participação e da autonomia, estabelece o diálogo entre diferentes sujeitos construtores do espaço escolar, permite a consolidação de uma visão conjunta e negociada da qualidade socialmente referenciada. Autores como Gadotti (2001), Veiga (1997) e Paro (2006) compreendem, igualmente, que o desenvolvimento da participação e autonomia através de uma gestão democrática proporciona a formação de uma escola pública de qualidade, socialmente referenciada no processo de debate e diálogo das questões internas, externas, locais e gerais que envolvem a escola, rompendo com a alienação sobre os condicionantes econômicos e políticos da educação. (VEIGA, 1997, p.18). A luta pela gestão democrática na educação não é tema recente, sendo centro dos debates entre as décadas de 1960 e 1980, presente, por exemplo, nas disputas pela constituinte de 1988, período em que finalmente se consagra a gestão democrática do ensino público, instituída na Constituição Federal. A implantação da gestão democrática como forma de gerenciamento da escola pública, assumida como princípio de ensino com a Constituição Federal de 1988 e reafirmada com a Lei de Diretrizes e Bases da Educação Nacional nº 9.394/96, implica na organização e fortalecimento de mecanismos para efetivação da participação da comunidade na escola.

Mas, obviamente, apenas a existência da lei, como evidencia Gadotti (2001), não estabelece a democracia, é preciso que todos os membros da comunidade escolar se apropriem de seu significado político, numa construção contínua e coletiva através de espaços dinâmicos abertos ao diálogo e ao conflito saudável entre as diferentes formas de se enxergar nesse espaço formativo. Segundo 


\section{Educere "Educare \\ Revista de EduCAČ̃̃o}

Programa de Pós-Graduação em Educação - Universidade Estadual do Oeste do Paraná

Gadotti (2006), a autonomia no contexto das dinâmicas colegiadas da educação no Brasil é tema eminentemente político, pois relaciona-se à crítica quanto ao papel do Estado, abrindo ou não espaços de legitimação no interior de escolas e conselhos. Gadotti (2006) afirma que o conselho de escola é essencial para a o desenvolvimento do espaço de vez, voz e voto de sua comunidade, ou seja, é um sistema no qual os próprios colaboradores administram a instituição, no caso, a escola. A ideia de autonomia está relacionada à ideia de democracia e cidadania e, como disse Bernard Charlot durante um debate no III Fórum Mundial de Educação: "Não há democracia sem escola pública forte, afinal somente com uma escola pública de qualidade é possível construir um verdadeiro Estado Republicano" (CHARLOT, 2004 apud GADOTTI, 2006). A autonomia admite a diferença e por isso supõe a parceria e a construção conjunta.

Todo espaço que se propõe a ser realmente dialógico enfrenta tensões e conflitos. Haverá resistências, embates, negociações no encaminhamento de demandas sociais em colegiados onde a autonomia e participação são elementos transversais. Trata-se de um processo trabalhoso, demorado, mas necessário, que é o de assumir em suas próprias mãos a gestão coletiva, o que exige permanente relação dialógica entre escola-comunidade-sociedade. Essa dialogicidade manifesta-se claramente na relação entre os contextos macro e micro nos debates, ou seja, não se pode afastar as questões imediatas e pontuais do universo escolar das macroquestões sociais, tampouco se pode ignorar a cultura local e sua história, trazendo, de cima para baixo, diretrizes gerais. A partir das questões sociais mais gerais, a comunidade escolar pode discutir sua própria realidade e como esta se insere e se conecta com aquela outra (LIMA, 2015b).

Um conjunto de reformas educacionais ao longo da década de 1990, não só no Brasil como em diversos países, orquestrada pelas agências multilaterais de financiamento (Comissão Econômica para a América Latina e Caribe - CEPAL - e Banco Mundial), trouxe um novo discurso e novas práticas que buscavam "modernizar" a escola, tornando-a mais "eficiente" (PERONI, 2003). Essa 


\section{Educere Educare \\ Revista de EduCAČ̃̃o}

Programa de Pós-Graduação em Educação - Universidade Estadual do Oeste do Paraná

eficiência estava atrelada a lógica empresarial e implicou em um novo modelo de gestão da educação, burocratizando o cotidiano escolar, estabelecendo o diretor como gestor de estilo empresarial (FONSECA, 1995 et al., p. 53). Obviamente, essa visão de gestão e de qualidade entravou as possibilidades de uma gestão verdadeiramente participativa, democrática, diminuindo, por sua vez, o poder de ação de órgãos colegiados e seus instrumentos de legitimação.

A construção de um projeto democrático de educação voltado para a transformação social deve necessariamente não colocar à margem a voz de grupos socialmente representados, uma vez que a democracia representativa é o fio condutor da "democracia na forma da lei", mas, se instrumentalizado pela lógica autocrática e burocratizante do projeto hegemônico de educação, torna-se, na maioria das vezes, apenas um procedimento técnico formal. Nos dias atuais existe uma tensão entre essas duas perspectivas - tanto no interior das escolas quando da constituição de instrumentos de legitimação do Projeto Político-Pedagógico da escola como um dos canais da gestão democrática, quanto na composição de conselhos que deveriam ter como centralidade a defesa de uma educação socialmente referenciada para e pelo cidadão.

Autonomia só se torna possivel ao se compartilhar poderes, rompendo com a lógica de administrador-administrado, própria das organizações tradicionais de mercado, abrindo-se para a participação substantiva. Repensar a qualidade como socialmente referenciada é repensar a gestão democrática e a construção de seus espaços e instrumentos, é resgatar a importância da qualidade dos processos em detrimento da quantidade, chocar-se com o produtivismo, visando a autonomia dos sujeitos envolvidos, já que gestão democrática e educação emancipadora não se separam e voltar-se para "levar" a escola e o seu sistema adiante (organizando espaços, tempos e recursos), mas, essencialmente, comprometer-se com a educação de qualidade dos estudantes, finalidade primeira e última da escola pública. A democracia envolve participação, ou seja, poder compartilhado, construção coletiva (RAIMANN, 2015). 


\section{Educere Educare \\ Revista de EduCAC̄̃̃o}

Programa de Pós-Graduação em Educação - Universidade Estadual do Oeste do Paraná

A participação da sociedade civil é espaço central que pode possibilitar o rompimento da comunidade (do município, da escola, etc.) de seu isolamento e permitir o debate em contextos mais amplos que envolvam os rumos da sociedade e seu projeto de educação, e ainda fortalecer os mecanismos de gestão democrática, por meio de seus conselhos de educação. A educação escolar regular, distinta da educação livre, é regular porque está sub lege e seus certificados e diplomas possuem validade oficial. Suas funções, voltadas para essa finalidade, são um múnus público, e devem ser levadas adiante por um órgão colegiado, formado por membros que se reúnam em uma colegialidade, horizontalmente organizada. Sob coordenação não hierárquica, todos os membros se situam no mesmo plano concorrendo, dentro da pluralidade própria de um Conselho, para a formação de uma vontade majoritária ou consensual do órgão (CURY, 2006).

Bobbio (1997) afirma que o único modo de se chegar a um acordo quando se fala de democracia, entendida como contraposta a todas as formas de governo autocrático, é o de considerá-la caracterizada por um conjunto de regras (primárias ou fundamentais) que estabelecem quem está autorizado a tomar as decisões coletivas e com quais procedimentos. Ressalta também a importância de que este indivíduo chamado à representatividade tenha resguardados direitos de liberdade, de opinião, de expressão das próprias opiniões, direitos sub lege, que exerce dentro de limites derivados do reconhecimento constitucional dos direitos "invioláveis" do indivíduo. Com esta concepção de democracia, percebemos o papel dos conselhos municipais de educação como objetos de consolidação destes espaços democráticos, até mesmo por sua definição etimológica e histórica.

Um conselho municipal de educação conforme sua finalidade constitucional e pautado nas diretrizes LDBEN deve se constituir como espaço de participação e democracia na proposta e acompanhamento da tipologia e qualidade de educação a ser ofertada ao seu munícipe. A participação da sociedade nas instâncias locais, como fazer-se presente no conselho escolar e no conselho municipal de educação, 


\section{Educere "Educare \\ Revista de EduCAČ̃̃o}

Programa de Pós-Graduação em Educação - Universidade Estadual do Oeste do Paraná

abre espaço, mesmo que conflitual, para o debate em torno da qualidade que se espera da educação e se empenha em alcançá-la (LOPES, 2016, p. 9383) numa perspectiva de gestão democrática.

\section{PERSPECTIVAS DE GESTÃO DEMOCRÁTICA NOS CME: ALGUMAS PONTUAÇÕES}

O termo gestão, segundo Cury (2000) tem sua raiz etimológica em ger, que significa fazer brotar, germinar, fazer nascer. Da mesma raiz provém o termo genitor (a), isto é, aquele que gera ou faz nascer. Consequentemente, aplicada à instituições escolar sob o enfoque democrático, gestão pode significar a geração de um novo modo de administrar, que, então, pode traduzir a comunicação, o diálogo e a democracia. Com esta definição entendemos que a gestão ocorre com um ou mais interlocutores que buscam soluções para o governo da educação, tendo como parâmetro a justiça. Em seu contexto histórico, a gestão democrática nos direciona para uma prática de ação onde, os gestores atuam de forma contrária ao paternalismo e ao autoritarismo (modos de agir que ignoram a igualdade entre as pessoas). Esta condição que impede uma cidadania ativa, impõe limites aos direitos, embora possam existir previsibilidade de sua existência, ignora a conquista das deliberações individuais e coletivas e reforça elitismo dos que se consideram acima dos demais.

Se a noção da gestão democrática sob os direitos políticos é uma conquista da modernidade, ela se torna mais plena de significado para o Brasil quando se tem a sua origem próxima em nossa história educacional (CURY, 2002, p. 166). Convém lembrar que as promessas de democratização social e política nos anos de 1960 , se perderam em meio ao golpe de 1964. Neste período a educação se constituiu de comandos autoritários e mandamentos legais, tais como Atos Institucionais, decretos-leis e supressão de direitos civis. Esta forma de gestão deturpada, acabou por se refletir no interior da escola e suas instituições, sob a forma do "vigiar e punir". Acima do diálogo se impunha a obediência temerária. 


\section{Educere "Educare \\ Revista de EduCAČ̃̃o}

Programa de Pós-Graduação em Educação - Universidade Estadual do Oeste do Paraná

Diante deste momento histórico, um novo ordenamento jurídico se originou com projeção de bases democráticas, por meio das mobilizações e dos movimentos de oposição ao regime militar, que contou com ampla participação popular, principalmente do professorado, culminando com princípios importantes para a democracia em 1988, por meio da Constituição. Princípios da legalidade, impessoalidade, moralidade, publicidade e eficiência. Definidos por CURY (2002), como princípios que efetivados, colocaram a transparência, o diálogo, a justiça e a competência como transversais à cidadania democrática e republicana. Na Lei de Diretrizes e Bases da Educação Nacional, Lei n.9.394/96, a gestão democrática é revelada quando se refere ao pacto federativo nos termos da autonomia dos entes federados, assim como nos artigos 14 e 15 que definem o trabalho em equipe de toda a comunidade escolar, centrada na palavra participação.

A gestão democrática também tem espaço garantido na lei $\mathrm{n}^{\circ} 10.127$, de 9 de janeiro de 2001, conhecida como Plano Nacional de Educação (PNE). O Plano trata da gestão dos recursos, eficiência, transparência e modernidade dos meios. O texto também dá ênfase ao pacto federativo, destacando a importância do aprimoramento contínuo do regime de colaboração, que resultará na divisão de responsabilidades previstas na Constituição. Cury (2002), evidencia que a gestão democrática dos Conselhos de Educação não pode deixar de estar revestida de competência técnica e representatividade, do compromisso com a proposta de sociedade emanada da vontade e diretriz popular e sua efetiva participação.

\section{CONSIDERAÇÕES FINAIS}

Os conselhos de educação são considerados espaços legítimos de gestão democrática na politica educacional. O debate a respeito de conselhos municipais de educação, das últimas décadas no Brasil, manifesta-se frequentemente por meio de movimentos com o objetivo de superar a herança colonial da centralização de poder, das decisões que desconsideram a capacidade da comunidade local para gerir seus caminhos. Contra este centralismo, muitos educadores se levantaram, 


\section{Educere "Educare \\ Revista de EduCAČ̃̃o}

Programa de Pós-Graduação em Educação - Universidade Estadual do Oeste do Paraná

como por exemplo Anísio Teixeira, que defendia que a escola primaria deveria ter seus encargos passados para o governo municipal, pois a relação entre comunidade e escola teria mais coesão. Constituído por uma assembleia de pessoas, o conselho tem natureza pública, para proceder de forma a aconselhar, dar parecer, deliberar com relação a questões de interesse público em sentido amplo ou restrito. Este representa a pluralidade, expressando as vontades e vozes do grupo social. Estas manifestações ocorrem inicialmente por meio de assembleias legitimadas, e posteriormente por normas escritas sobre assuntos de interesse do Estado. Os conselhos, portanto, funcionam sob a égide de alguns princípios como: o caráter público, a voz plural representativa da comunidade, a deliberação coletiva, a defesa dos interesses da cidadania e o sentido de pertencimento (BRASIL, 2004).

Sendo assim, os conselheiros necessitam aprofundar-se em estudos e investigações que os conduziram aos profissionalismos da função, ampliando os conhecimentos específicos da função e suas tarefas, descartando o amadorismo, diante do ordenamento jurídico que se impõe. A ação dos conselheiros ocorrerá de acordo com as finalidades maiores da educação nacional, observando os objetivos do Estado de Direito, de forma a garantir limites do poder do Estado e a elevação da consciência e da participação dos cidadãos. Muitas funções são igualmente meritórias neste colegiado, como a consultiva e de assessoramento, e com especial destaque a função normativa, que se dá por meio de Pareceres ${ }^{\mathrm{i} e}$ Resoluções, ${ }^{i i}$ que devem sempre ser compativeis com as legislações das quais são decorrentes e principalmente com a que lhe dá o fundamento maior de validade: a Constituição Federal. A função normativa, assessora a própria lei, para atender os interesses coletivos de cidadania.

Os conselhos municipais de educação contribuem de forma especial para que as leis sejam contextualizadas, regularizadas em seus aspectos institucionais e específicos, pois nenhuma lei é suficientemente capaz de fazê-lo por si só. Para tanto este colegiado conta com a discrição como poder administrativo, entendendo 


\section{Educere Educare \\ Revista de EduCAČ̃̃o}

Programa de Pós-Graduação em Educação - Universidade Estadual do Oeste do Paraná

por discrição a capacidade de distinguir, ou discernir. Esta permitirá ao administrador certa liberdade para definir a melhor maneira de respeitar a norma legal, ao mesmo tempo em que se observa as situações concretas daquele espaço social, concreto de experiências únicas. Em decorrência desta condição, (CURY, 2006), considera necessário destacar que o Conselho, portanto, deve articular à sua legalidade a busca de uma legitimidade, e ainda acrescenta que o caminho do conselho deve ser trilhado com, pelo menos, três veios a fim de produzir normas que não possam ir além da lei: o do direito, o do estudo dos problemas educacionais e o da relação entre ambos. Neste sentido, este colegiado deve ter em sua composição, membros capazes de zelar pelo cumprimento das leis e de assegurar a participação da sociedade no aperfeiçoamento da educação nacional.

Os conselhos agirão frente a muitas competências como: aprovação de propostas pedagógicas, equivalência de estudos, autorização de funcionamento de escolas de educação infantil da rede privada, aprovação de regimentos escolares e outros. Esse direito deve ser respeitado no interior do conselho de educação, por seus conselheiros, agentes públicos de um serviço público, condição para que as atuais e novas gerações possam se beneficiar do acesso aos conhecimentos historicamente construídos, aos valores próprios dos direitos humanos e a cidadania. Com a mediação dos conselhos, (CURY, 2006), afirma que a educação se torna uma síntese entre igualdade e diferença. Mais do que meros executores de políticas, os cidadãos querem ser ouvidos nos momentos de elaboração das políticas públicas, assim como, nos momentos de tomadas de decisão. A participação é a forma concreta da democracia. 


\section{Educere Educare \\ ReviSTA De EduCAC̄̃̃o}

Programa de Pós-Graduação em Educação - Universidade Estadual do Oeste do Paraná

\section{REFERÊNCIAS}

ALLEBRANDT, S. L. Conselhos Municipais: potencialidades e limites para a efetividade e eficácia de um espaço público para a construção da cidadania interativa. In: Enanpad, 27, 2003, Atibaia. Anais... Atibaia-SP: Anpad, 2003. CDROM.

AZEVEDO, J. L. de. Notas sobre a análise da gestão democrática da educação e da qualidade de ensino no contexto das políticas educativas. RBPAE, v. 27, n. 3, p. 365-588, set./dez, 2011. Disponivel em: http://seer.ufrgs.br/index.php/rbpae/article/view/26412/15404. Acessado em 20.07.017.

BARROSO, J. O Estado, a educação e a regulação das políticas públicas. Educação \& Sociedade, vol.26, n.92, 2005. Disponível em: http://www.scielo.br/pdf/es/v26n92/v26n92a02.pdf. Acessado em 20.07.017.

BOBBIO, N. O futuro da democracia: uma defesa das regras do jogo. Rio de Janeiro: Paz e Terra, 1986.

BORDINGNON, G. Gestão da educação no municipio: sistema, conselho e plano. São Paulo: Editora e Livraria Instituto Paulo Freire, 2009.

BRASIL. Constituição (1988). Constituição da República Federativa do Brasil. Brasília, DF: Senado, 1988.

BRASIL. Presidência da República. Lei de Diretrizes e Bases da Educação Nacional n 9394/96. Brasília, 1996.

BRASIL. Programa nacional de fortalecimento dos conselhos escolares. Portal Mec, 2004.

http://portal.mec.gov.br/seb/arquivos/pdf/Consescol/ce_gen.pdf. Acessado em: 20 de julho 2017.

CURY, C. R. J. Conselhos de educação: fundamentos e funções. Revista Brasileira de Politica e Administração da Educação, v. 22, n. 1, p.41-67, fev. 2006. Disponivel em: http://seer.ufrgs.br/index.php/rbpae/article/view/18721/10944. Acesso em: 12 mar. 2017.

CURY, C.R.J. Gestão democrática da educação: exigências e desafios. Revista Brasileira de Politica e Administração da Educação, v. 18, n. 2, jul./dez. 2002. Disponível 


\section{Educere Educare \\ ReVISTA DE EduCACÃ̃o}

Programa de Pós-Graduação em Educação - Universidade Estadual do Oeste do Paraná

http://www.seer.ufrgs.br/rbpae/article/viewFile/25486/14810. Acessado em 12.03.2017.

CURY, C.R.J. Conselhos escolares: uma estratégia de gestão democrática na escola pública. Ministério da Educação e Cultura. Secretaria da Educação Básica. Brasília: DF, 2004, p.35-40.

DAVOK, D. F. Qualidade em educação. Avaliação, vol.3, n.12, 2007. Disponível em: <http://www.scielo.br/pdf/aval/v12n3/a07v12n3.pdf>. Acessado em: 10 jul 2017.

FONSECA, J. P. da.; et al. Planejamento Educacional Participativo. In: Revista da Faculdade de Educação da USP, v. 21, n 1, p. 79-112, jan/jun. 1995. Disponível em: http://www.revistas.usp.br/rfe/article/view/33555/36293. Acessado em 10 jul 2017.

FONSECA, M. Políticas públicas para a qualidade da educação brasileira: entre o utilitarismo econômico e a responsabilidade social. Gestão institucional e qualidade social da educação. Caderno Cedes, vol.29, n.78, 2009. Disponível em: http://www.scielo.br/pdf/ccedes/v29n78/v29n78a02. Acessado em 10 jul 2017.

FRIGOTTO, G. A formação e a profissionalização do educador: Novos desafios. In: GENTILI, P.; SILVA, T. T. (Orgs.). Escola S.A.: Quem ganha e quem perde no mercado educacional do neoliberalismo. Brasília: CNTE, 1996.

GADOTTI, M. Concepção dialética da educação: um estudo introdutório. São Paulo: Cortez, 2001.

GADOTTI, M. Escola cidadã. 11. ed. São Paulo: Cortez, 2006.

GENTILI, P. O discurso da "qualidade" como nova retórica conservadora no campo educacional. In: GENTILI, P.; SILVA, T. T. (Ed.). Neoliberalismo, qualidade total e educação (p. 111-117). Petrópolis: Vozes, 1999.

GOHN, M. G. Conselhos gestores na política social urbana e participação popular. Cadernos Metrópole n. 7, p. 9-31, $1^{\circ}$ sem. 2002. Disponível em: https://revistas.pucsp.br/index.php/metropole/article/download/9257/6867. Acessado em 10 jul.2017.

GOHN, M.G. Educação não-formal, participação da sociedade civil e estruturas colegiadas nas escolas. Ensaio: aval. pol. públ. Educ., Rio de Janeiro, v.14, n.50, p. 27-38, jan./mar. 2006. Disponível em: 


\section{Educere Educare \\ ReVISTA DE EduCAC̄̃̃o}

Programa de Pós-Graduação em Educação - Universidade Estadual do Oeste do Paraná

http://escoladegestores.mec.gov.br/site/8-biblioteca/pdf/30405.pdf . Acessado em 10 jul.2017.

LIMA, A. B. de. PPP - Participação, gestão e qualidade da educação. Uberlândia/MG: Ed. Assis, 2015a.

LIMA, P. G. O PPP como instrumento do exercício participativo e democrático. In: LIMA, A.B. de. PPP - Participação, gestão e qualidade da educação. Uberlândia/MG: Ed. Assis, 2015b.

LOPES, N. A. A Qualidade socialmente referenciada do ensino e o conselho municipal de educação em Jataí/GO. In: XVIII ENDIPE - Didática e Prática de Ensino no contexto político contemporâneo: cenas da Educação Brasileira. Goiás. p. 9382-9386, 2016. Disponível em: http://www.ufmt.br/endipe2016/downloads/233997437513.pdf. Acessado em: Acessado em 10 jul.2017.

PARO, V. H. Gestão democrática da escola pública. 3 ed. São Paulo: Ática, 2006.

PARO, V. H. Gestão democrática da escola pública. São Paulo: Editora Ática, 1997.

PERONI, V. M. Breves considerações sobre a redefinição do papel do Estado. In PERONI, V. M. Política educacional e papel do Estado no Brasil dos anos 1990. São Paulo: Xamã, 2003.

RAIMMAN, A. PPP: a gestão e a qualidade da educação. In: LIMA, A.B. de. PPP Participação, gestão e qualidade da educação. Uberlândia/MG: Ed. Assis, 2015a.

SAVIANI, D. Organização da educação nacional: Sistema e Conselho Nacional de Educação, Plano e Fórum Nacional de Educação. Educação \& Sociedade, v. 31, n. 112, p. 769-788, jul-set., Campinas, 2010. Disponivel em: http://www.scielo.br/pdf/es/v31n112/07.pdf. Acessado em 12.03.2017.

SAVIANI, D. Sistemas de ensino e planos de educação: o âmbito dos Municípios. Educação \& Sociedade, Campinas, ano XX, n. 69, p. 119-136, dez.1999. Disponivel em: http://www.scielo.br/pdf/es/v20n69/a06v2069.pdf. Acesso em: 12.03.2017.

SILVA, M. A. da. Qualidade social da educação pública: algumas aproximações. Caderno CEDES vol. 29 no 78 mai/ago. 2009. Disponivel em: http://www.scielo.br/ scielo.php?script=sciarttext\&pid=S010132622009000200005. Acessado em: 10 jul 2017. 


\section{Educere Educare \\ RevisTA De EduCAC̄̃̃o}

Programa de Pós-Graduação em Educação - Universidade Estadual do Oeste do Paraná

TEIXEIRA, E. O poder local e o global: limites e desafios da participação cidadã. São Paulo/Recife/Salvador: Cortez/EQUIP/UFBA, 2001. Disponível em: http://www.bibliotecadigital.abong.org.br/bitstream/handle/11465/1744/252. pdf?sequence=1\&isAllowed=y. Acesso em: 12.06.2017.

TEIXEIRA, L. H. Conselhos municipais de educação: autonomia e democratização do ensino. Cadernos de Pesquisa, v. 34, n. 123, set./dez. 2004. p. 691-708. Disponivel em: http://www.scielo.br/pdf/cp/v34n123/a09v34123.pdf. Acesso em: 12.06.2017.

VASCONCELOS, M. C. C. Conselhos Municipais de Educação: criação e implantação em face das novas atribuições dos sistemas municipais de ensino. Desafios da educação municipal. Rio de Janeiro: DP\&A, p. 107-122, 2003

VEIGA, I. P. A. (Org.), Projeto político-pedagógico: uma construção possível. Campinas, SP: Papirus, 1997.

\footnotetext{
i Um parecer é um ato enunciativo pelo qual um órgão emite um encaminhamento fundamentado sobre uma matéria de sua competência. Quando homologado por autoridade competente da administração pública ganha força vinculante.

iiA resolução é um ato normativo emanado de autoridade específica do poder executivo com competência em determinada matéria regulando-a com fundamento em lei. O Conselho Nacional de Educação, por lei, é um órgão com poderes específicos para expedir uma resolução (CURY, 2006, p. 43).
}

Recebido em: 10/09/2017

Aprovado em: 18/01/2018 